Sciences

Vol. 07, No. 04, pp. 115-131, December 2014

\title{
THEORETICAL DESIGN OF MIMO TRANSCEIVER AND IMPLEMENTATION ITS TRANSMITTER USING FPGA
}

\author{
KHALID AWAAD HUMOOD ${ }^{1}$, ADHAM HADI SALEH ${ }^{2}$, WA'IL A. H. HADI ${ }^{3}$ \\ ${ }^{1}$ Lecturer, ${ }^{2}$ Assistant Lecturer, College of Engineering, Diyala University \\ ${ }^{3}$ Assistant Professor, Department of Electrical Engineering, University of Technology
}

(Received: 14/1/2014; Accepted: 25/2/2014)

\begin{abstract}
The use of multiple transmit and receive antennas (MIMO system) is widely accepted in recent years, as a promising technology for future wireless communication, to achieve higher data rates independently of transmission power and bandwidth, with improve system reliability through increasing diversity. This research presents the design and implementation of a multiple antenna wireless communications system using Xilinx Field Programmable Gate Array (FPGA) .The proposed design based on Alamouti's transmit diversity scheme which is a space-time block code (STBC) with two transmit antennas and an arbitrary number of receive antennas. The implementation demonstrates the space-time code in a baseband system with two antennas for transmitter and receiver. The encoding and decoding algorithms are implemented using VHDL, Spartan 3A / $3 \mathrm{AN}$ is used to implement transmitter part, where the Virtex $2 \mathrm{P}$ is used to complete the receiver part design theoretically. Finally the design MIMO systems are implemented successfully.
\end{abstract}

Keywords: MIMO System, STBC, Alamouti's scheme, FPGA.

\section{1- INTRODUCTION}

In recent years, Multiple-Input Multiple-Output (MIMO) systems have emerged as a most promising technology in digital communication system. The core idea behind MIMO is that signals sampled in the spatial domain at both ends are combined in such a way that they either create effective multiple parallel spatial data pipes (therefore increasing the data rate), and/or add diversity to improve the quality (bit error rate) of the communication ${ }^{(1,2)}$. A general model of a MIMO system is shown in Figure $(1)^{(3,4)}$. 


\section{2- ALAMOUTI SYSTEM WITH TWO TRANSMIT AND TWO RECEIVE ANTENNAS}

Alamouti technique is a simple transmit diversity scheme which improves the signal quality at the receiver on one side of the link by simple processing across two transmit antennas on the opposite side. The obtained diversity order is equal to applying MaximalRatio Receiver Combining (MRRC) with two antennas at the receiver. The scheme can be easily generalized to two transmit antennas $M$ receive antennas to provide a diversity order of $2 \times \mathrm{M}$. This is done without any feedback from the receiver to the transmitter and with small computation complexity $(5,6$, and 7$)$. The scheme requires no bandwidth expansion, as redundancy is applied in space across multiple antennas, not in time or frequency ${ }^{(9,10)}$.

The encoder for Alamouti scheme with two transmit antennas and two receive antenna is interpreted here. In general case, $M$ receive antennas can be used .In Alamouti encoding scheme, during any given transmission period two signals are transmitted simultaneously from two transmit antennas $(11,12)$.

The encoder takes two modulated symbols $s_{1}$ and $s_{2}$ at a time. The transmit matrix $S$ is given by equation $(1)^{(11,12,13)}$.

$\mathrm{S}=\left(\begin{array}{cc}\mathrm{S}_{1} & -\mathrm{s}_{2}^{*} \\ \mathrm{~s}_{2} & \mathrm{~s}_{1}^{*}\end{array}\right)$

Where $s^{*}$ is complex conjugate of $s$. During the first transmission period, two signals $s_{1}$ and $s_{2}$ are transmitted simultaneously from the first and second antennas, respectively. In the second transmission period, signal $-s_{2}^{*}$ is transmitted from first antenna and signal $s_{1}^{*}$ from second antenna as shown in Table (1). It is clear that the encoding process is done in

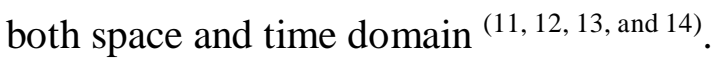

The code belongs to a special subclass of STBCs known as an Orthogonal Space Time Block Codes (OSTBC). The code matrices of OSTBCs satisfy the following constraint $(11,15,16)$.

$X X^{H}=\sum_{n=1}^{n s}\left|s_{n}\right|^{2} \cdot(\alpha I)$

where $n s$ is the number of symbols, $s_{n}$ is the nth complex symbol, $\alpha$ is an arbitrary constant and $(\cdot)^{H}$ denotes the Hermitian conjugate. $(11,15,16)$ The received matrix in a $2 \times 2$ system can be written as:

$Y=\left[\begin{array}{ll}\mathrm{h}_{1} & \mathrm{~h}_{2} \\ \mathrm{~h}_{3} & \mathrm{~h}_{4}\end{array}\right]\left[\begin{array}{rr}\mathrm{s}_{1} & -\mathrm{s}_{2}^{*} \\ \mathrm{~s}_{2} & \mathrm{~s}_{1}^{*}\end{array}\right]+\left[\begin{array}{ll}\mathrm{n}_{1} & \mathrm{n}_{2} \\ \mathrm{n}_{3} & \mathrm{n}_{4}\end{array}\right]$

The received signals at the two receive antennas denoted by $r_{1}, r_{2}, r_{3}$ and $r_{4}$ for $t$ and $t$ $+\mathrm{T}$, respectively, can be expressed as :

$\mathrm{r}_{1}=\mathrm{h}_{1} \mathrm{~s}_{1}+\mathrm{h}_{2} \mathrm{~s}_{2}+\mathrm{n}_{1}$ 


$$
\begin{aligned}
& \mathrm{r}_{2}=-\mathrm{h}_{1} \mathrm{~s}_{2}^{*}+\mathrm{h}_{2} \mathrm{~s}_{1}^{*}+\mathrm{n}_{2} \\
& \mathrm{r}_{3}=\mathrm{h}_{3} \mathrm{~s}_{1}+\mathrm{h}_{4} \mathrm{~s}_{2}+\mathrm{n}_{3} \\
& \mathrm{r}_{4}=-\mathrm{h}_{3} \mathrm{~s}_{2}^{*}+\mathrm{h}_{4} \mathrm{~s}_{1}^{*}+\mathrm{n}_{4}
\end{aligned}
$$

Figure (2) shows the two transmit and two receive antennas scheme ${ }^{(8,37, \text { and 39) }}$. where $\mathrm{r}_{1}, \mathrm{r}_{2}, \mathrm{r}_{3}$ and $\mathrm{r}_{4}$ are notions of received signals and $\mathrm{n}_{1}, \mathrm{n}_{2}, \mathrm{n}_{3}$, and $\mathrm{n}_{4}$ represent the noise signals in received the signals. If the channel fading attenuations can be perfectly recovered at the receiver, the receiver will use them as the channel state information (CSI) in the decoder $^{(11,12, \text { and } 16)}$. The combined signals can be represented as follows :

$$
\begin{aligned}
& \tilde{\mathrm{s}}_{1}=h_{1}^{*} \mathrm{r}_{1}+\mathrm{h}_{2} \mathrm{r}_{2}^{*}+\mathrm{h}_{3}^{*} \mathrm{r}_{3}+\mathrm{h}_{4} \mathrm{r}_{4}^{*} \\
& \tilde{\mathrm{s}}_{2}=\mathrm{h}_{2}^{*} \mathrm{r}_{1}-\mathrm{h}_{1} \mathrm{r}_{2}^{*}+\mathrm{h}_{4}^{*} \mathrm{r}_{3}-\mathrm{h}_{3} \mathrm{r}_{4}^{*}
\end{aligned}
$$

Substituting equations (4), (5), (6) and (7), in equations (8) and (9) the combined signals can be written as shown below:

$$
\begin{aligned}
& \tilde{s}_{1}=\left(\left|h_{1}\right|^{2}+\left|h_{2}\right|^{2}+\left|h_{3}\right|^{2}+\left|h_{4}\right|^{2}\right) s_{1}+h_{1}^{*} n_{1}+h_{2} n_{2}^{*}+h_{3}^{*} n_{3}+h_{4} n_{4}^{*} \\
& \tilde{s}_{2}=\left(\left|h_{1}\right|^{2}+\left|h_{2}\right|^{2}+\left|h_{3}\right|^{2}+\left|h_{4}\right|^{2}\right) s_{2}-h_{1} n_{2}^{*}+h_{2}^{*} n_{1}-h_{3} n_{4}^{*}+h_{4}^{*} n_{3}
\end{aligned}
$$

It can be seen that the estimation mostly depends on the magnitude or characteristic of the channels so that the scheme is resistant to phase changes. As the signal $\tilde{s}_{1}$ depends only on $s_{1}$ and $\tilde{\mathrm{s}}_{2}$ only on $s_{2}, s_{1}$ and $s_{2}$ can be decided by applying the maximum likelihood rule on $\widetilde{\mathrm{s}}_{1}$ and $\widetilde{\mathrm{s}}_{2}$ separately ${ }^{(9,11)}$. It is interesting to note that the combined signals from the two receive antennas are the simple addition of the combined signals from each receive antenna, i.e., the combining scheme is identical to the case with a single receive antenna ${ }^{(10)}$.

\section{3- DESIGN OF MIMO SYSTEM USING FPGA}

\section{1- Alamouti transmitter}

Figure (3) shows the block diagram of the Alamouti transmitter. It consists of three sub-blocks. Which are the serial-to-parallel converter, BPSK or QPSK modulator and Alamouti encoder. The input data is a composition of serial binary bits which are fed into the Alamouti transmitter design. The Alamouti transmitter design, manipulates these binary bits in such a manner that it follows the Alamouti's transmit diversity technique to produce outputs at two transmit antennas. At this point, take note that there is an assumption that the fading and inputs are constant for the duration of the encoding process.

Alamouti transmitter scheme can be represented as shown in Figure (4), Figure (5) shows internal circuit of Alamouti transmitter. 
The output of transmitter is illustrated in Table (2) where time simulation waveforms is shown in Figure (6) which have the imaginary part equal to (0), in the case of BPSK, while for QPSK it have another values.

\section{2-Alamouti receiver}

Alamouti receiver consists of Alamouti decoder, equalizer, BPSK or QPSK demodulator, serial-to-parallel and parallel to serial converter as shown in Figure (7). The received signal at the antenna is fed into the Alamouti decoder, where the signal is decoded according to the Alamouti's diversity technique. Upon the decoding process, the signal is then fed into equalizer which fed to BPSK or QPSK demodulator. Finally, data send parallel to serial converter to retrieve the original binary stream which was transmitted.

The receiver is assumed to have the knowledge of the channel characteristics. Therefore, the design does not require a channel estimator and Maximum Likelihood (ML) part of design. The transmitted signal is directly connected and the channel modeling modifies the transmitted signal to behave as it should be if it is transmitted over real wireless environment.

The Alamouti decoder, equalizer, BPSK demodulators and parallel-to-serial converter are combined to form the Alamouti receiver (Rx) as shown in Figure (8).

Figure (9) shows the Alamouti receiver internal circuit, it contains four units of equalizer, two units of BPSK and one serial-to-parallel converter circuit. Figure (10) shows the resulting output waveform.

\section{4-CHANNEL MODEL}

Channel model is designed to transmit data between, the transmitter and receiver antennas, make test on system, ensure system work as it should be and take the effect of mobile radio channel on system. Channel modeling is designed, since transmission is not done in a real wireless environment.

Therefore, the channel modeling is created because the transmitted signals needs to be modified to be in the representation of equations (4), (5), (6) and (7) before being received at the receiver end. This channel modeling has many real and imaginary parts for noise as shown in Figure (11), so it can be substituted the Additive White Gaussian noise (AWGN) to the channel after taking it from MATLAB.

Alamouti transmitter and Alamouti receiver connected together by channel module to get complete transmission system as shown in Figure (12) the output pin (read data out) is active high so when it gives logic (1) that will be refer to the output data which represented the received signal, which stay active high until it read two bit then back. 
Finally, for testing of the design, the input signal fed into the Alamouti transmitter module and the output is monitored at the designed Alamouti receiver module. The complete transmission output waveform is shown in Figure (13). Assume that there is no noise and interference present at the channel (ideal channel) at one state.

Spartan 3A / 3AN is used to implement transmission part, since it is available in the laboratory of the department, so the transmission part is implemented practically and getting the result, but when the receiver part get to implemented in this kit, it is found that the receiver part is too large to fit in Spartan 3A / 3AN, so Virtex 2P is used to complete the receiver part design theoretically.

The design summary of MIMO system with two transmitted and two received antennas is shown in Table (3) which explains the number of logic utilization in the design.

The proposed hardware design of MIMO system is a circuit design built to represent the architecture of Alamouti transmission circuit using FPGA hardware.

In Alamouti transmission circuit, there are 16 output line, so it is difficult to get this number of oscilloscopes, Therefore, eight LEDs which are available in board are used to represent the real part of transmission (one time to first antenna and second time to second antenna). Input data is represented by design binary signal generated using VHDL and connected it to Alamouti transmitter, where clock is represented by Pushbuttons switch available in platform

According to Table (2), when serial input data (00), the output data of first antenna at two time interval is $(80)_{\mathrm{HEX}}$, and the output data of second antenna at two time interval is $(80)_{\text {HEX }}$, as shown in Figure (14), Figure (15) shows the output data when serial input data is (11), and so on for another states.

\section{5- CONCLUSIONS}

MIMO system based on Alamouti's space-time code is designed and implemented successfully .The main conclusions obtained from this work can be summarized as follows:

1) The proposed system with two transmitter and two receiver antennas are coded and verified using VHDL successfully.

2) The inclusion of an Alamouti encoder in a transmitter design does not significantly increase its complexity.

3) The implementation of an Alamouti receiver is somewhat more challenging. These challenges are due to the constraints in implementing it on the FPGA, using many circuits 
each one have many internal circuits like decoder which contains add / subtract and control circuits, and equalizer circuit which have division and addition circuits.

4) This implementation is a part of an ongoing effort to develop an FPGA based multiple antenna wireless communications system, when used for getting high data rates and spectral efficiency. This design can be extended into different ways. First, it can be generalized to support multiple receive antennas using the decoding algorithm. It could be extended to support more than two transmit antennas using the generalization of Alamouti's code. Therefore, this work is proved that it is a quite feasible to design and implement an Alamouti code using commercially available FPGAs. This puts the possibility of further testing and research into MIMO systems.

5) The proposed design requires FPGA kit with high capacity like Virtex family for implementation.

6) Space-time codes have a simple architecture and can be implemented using FPGA.

\section{REFERENCES}

1) C. Oestges, and B. Clerckx, "MIMO Wireless Communications from Real-World Propagation to Space-Time Code Design”, Elsevier Ltd., 2008.

2) L. H. M Júnior, R. R. S Júnio, M. Silveira and S. E.Barbin, “An FPGA Implementation of Alamouti's Transmit Diversity Technique Applied to An OFDM System”, IEEE, 2006.

3) Adaham H. Saleh "MIMO System Over Wireless Mobile Radio Channel Using FBGA", M.Sc. Thesis, Department of Electrical Engineering, University of Technology, August, 2011.

4) E. Biglieri, R. Calderbank, A. Constantinides, A. Goldsmith, A. Paulraj, and H. V. Poor, "MIMO Wireless Communications", Cambridge University Press, USA, New York, 2007.

5) A. B. Gershman, and N. D. Sidiropoulos, "Space-Time Processing for MIMO Communications", John Wiley \& Sons Ltd, 2005.

6) A. Neubauer, J. Freudenberger, and V. Kuhn, "Coding Theory - Algorithms, Architectures, and Applications", John Wiley \& Sons, Ltd., 2007.

7) J. Mietzner, "Spatial Diversity in MIMO Communication Systems with Distributed or Co-located Antennas", Ph.D. Thesis, Albrecht's University, October, 2006.

8) F. D. Flaviis, L. Jofre, J. Romeu, and A. Grau, "Multi antenna Systems for MIMO Communications”, Morgan \& Claypool Publishers Series, 2008.

9) H. D. Saglam, "Simulation Performance of Multiple-Input Multiple -Output Systems Employing Single-Carrier Modulation and Orthogonal Frequency Division 
Multiplexing", M.Sc. Thesis, Naval Post Graduate School , Monterey, California, December, 2004.

10) S. M. Alamouti, “A Simple Transmit Diversity Technique for Wireless Communications", IEEE Journal on Selected Areas in Communications, Vol. 16, PP. 1451- 1458, October, 1998.

11) R. Abdolee, "Performance of MIMO Space-Time Coded System and Training Based Channel Estimation for MIMO-OFDM System”, M.Sc. Thesis, Department of Electrical Engineering, University of Malaysia, November, 2006.

12) M. Elzinati, "Space-time Block Coding for Wireless Communications”, PhD. Thesis, Surt University, Libya, August, 2008.

13) M. Jankiraman "Space-Time Codes and MIMO Systems", Artech House, Boston, London, 2004.

14) V. Tarokh, S. M. Alamouti and P. Poon "New Detection Schemes for Transmit Diversity with no Channel Estimation”, IEEE, 1998.

15) P. Mukilan, “An FPGA Implementation of Alamouti's Transmit Diversity Technique”, M.Sc. Thesis, Department of Electrical Engineering, University of Malaysia, May, 2008. 16) Ian Griffths, "FPGA Implementation of MIMO Wireless Communications System" B.Sc. Thesis. University of Newcastle, Australia, November, 2005.

Table (1): The encoding and transmission sequence for Alamouti STBC scheme

\begin{tabular}{|c|c|c|}
\hline & $\mathrm{Tx}_{1}$ & $\mathrm{Tx}_{2}$ \\
\hline $\mathrm{T}$ & $\mathrm{s}_{1}$ & $\mathrm{~s}_{2}$ \\
\hline $\mathrm{t}+\mathrm{T}$ & $-\mathrm{s}_{2}^{*}$ & $\mathrm{~s}_{1}^{*}$ \\
\hline
\end{tabular}


Table (2): The output data of Alamouti transmitter.

\begin{tabular}{|c|c|c|}
\hline $\begin{array}{l}\text { When serial input data } \\
\qquad(00)\end{array}$ & $\mathrm{T}$ & $\mathrm{t}+\mathrm{T}$ \\
\hline $\mathrm{Tx} 1$ & $(80) \mathrm{Hex}$ & $(80) \mathrm{Hex}$ \\
\hline $\mathrm{Tx} 2$ & $(80) \mathrm{Hex}$ & $(80) \mathrm{Hex}$ \\
\hline When serial input (01) & $\mathrm{T}$ & $t+T$ \\
\hline $\mathrm{Tx} 1$ & $(80) \mathrm{Hex}$ & (81) Hex \\
\hline $\mathrm{Tx} 2$ & $(7 \mathrm{~F}) \mathrm{Hex}$ & (80)Hex \\
\hline When serial input (10) & $\mathrm{T}$ & $\mathrm{t}+\mathrm{T}$ \\
\hline Tx1 & $(7 \mathrm{~F}) \mathrm{Hex}$ & (80)Hex \\
\hline $\mathrm{Tx} 2$ & (80)Hex & $(7 \mathrm{~F}) \mathrm{Hex}$ \\
\hline When serial input (11) & $\mathrm{T}$ & $\mathrm{t}+\mathrm{T}$ \\
\hline Tx1 & (7F)Hex & (81)Hex \\
\hline $\mathrm{Tx} 2$ & (7F)Hex & (7F)Hex \\
\hline
\end{tabular}

Table (3): Summary of MIMO system design with two transmitted and two received antennas.

\section{Device Utilization Summary (estimated values)}

\begin{tabular}{|c|c|c|c|}
\hline Logic Utilization & Used & Available & Utilization \\
\hline Number of Slices & 6151 & 13696 & $44 \%$ \\
\hline Number of Slice Flip Flops & 1401 & 27392 & $5 \%$ \\
\hline Number of 4 input LUTs & 11571 & 27392 & $42 \%$ \\
\hline Number of bonded IOBs & 198 & 644 & $30 \%$ \\
\hline Number of GCLKs & 1 & 16 & $6 \%$ \\
\hline
\end{tabular}




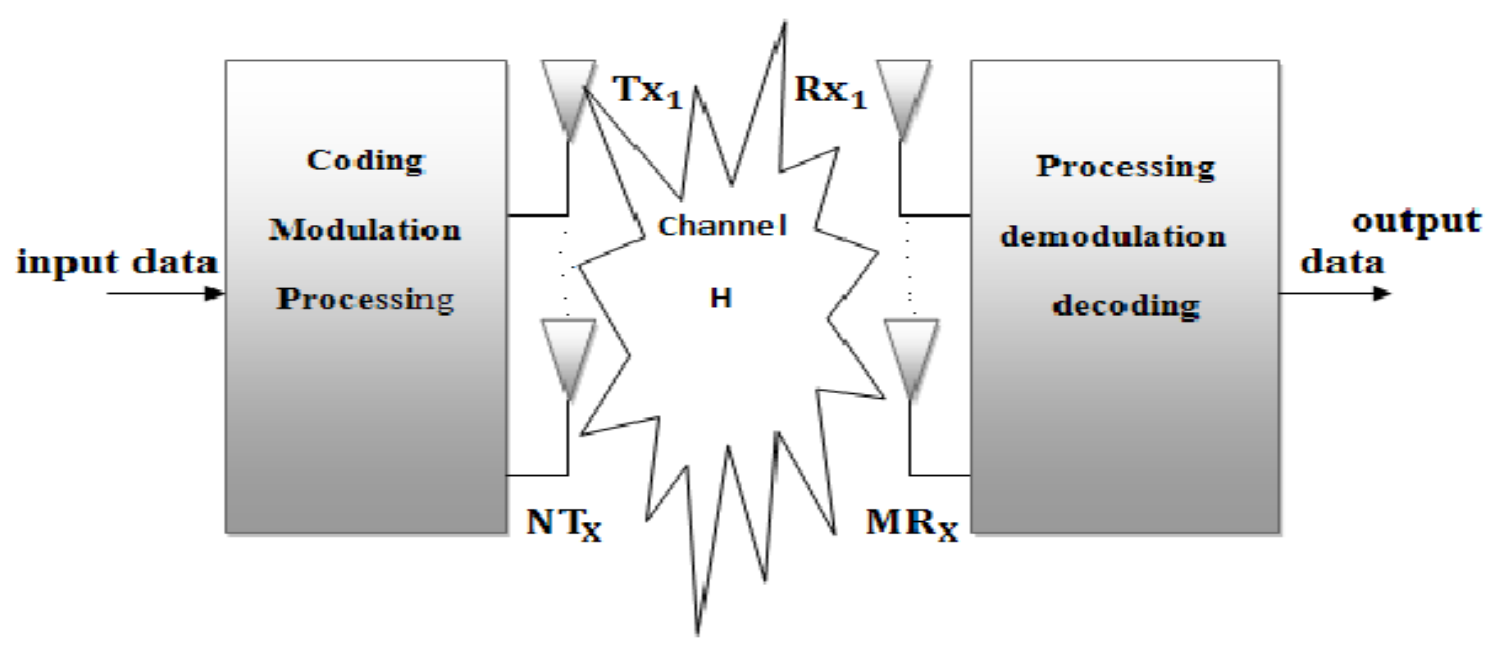

Figure (1): A general block diagram of a multiple input multiple output wireless communication system.

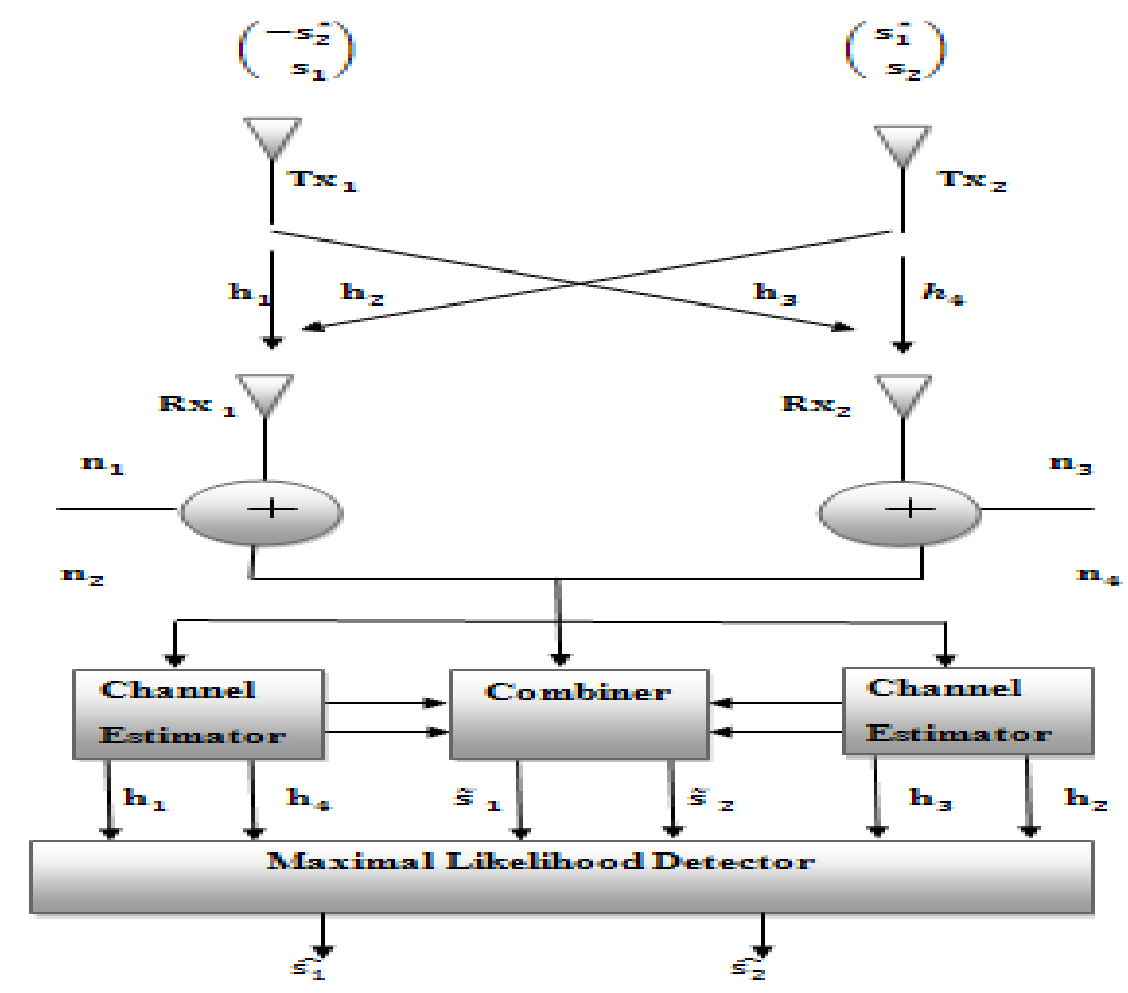

Figure (2): Space-time block code scheme with two transmit and two receive antennas. 


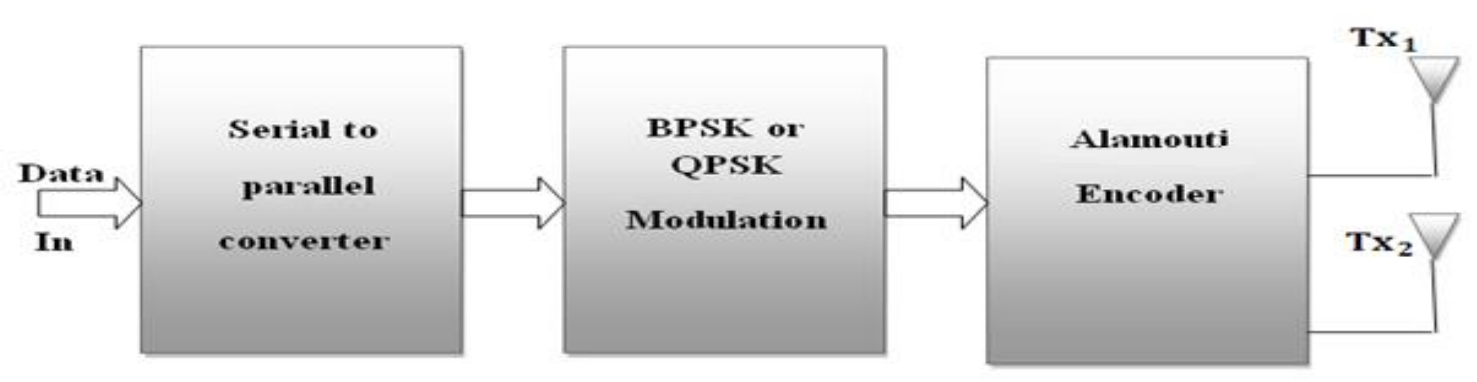

Figure (3): Block Diagram of Alamouti Transmitter.

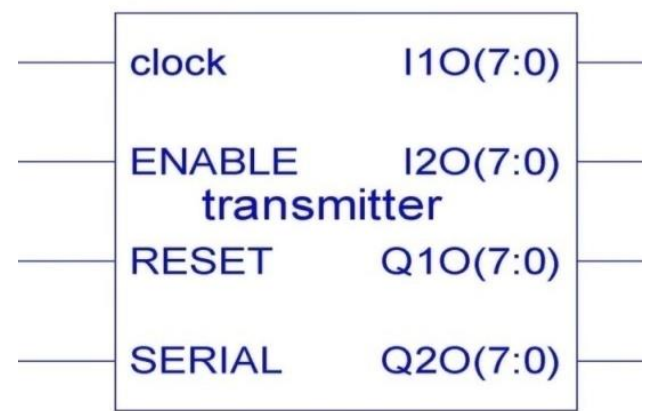

Figure (4): Alamouti transmitter.

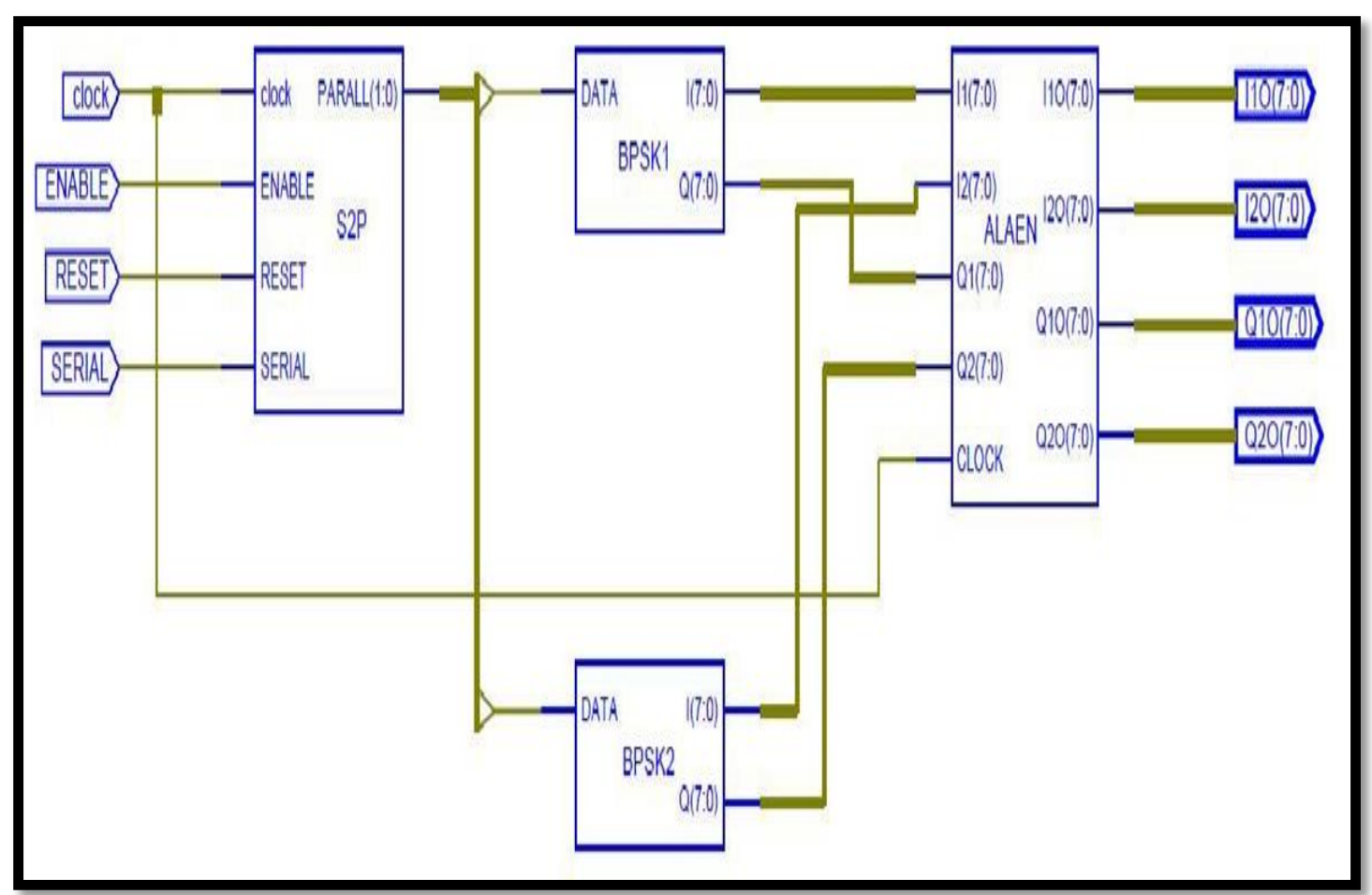

Figure (5): Internal circuit of Alamouti transmitter. 


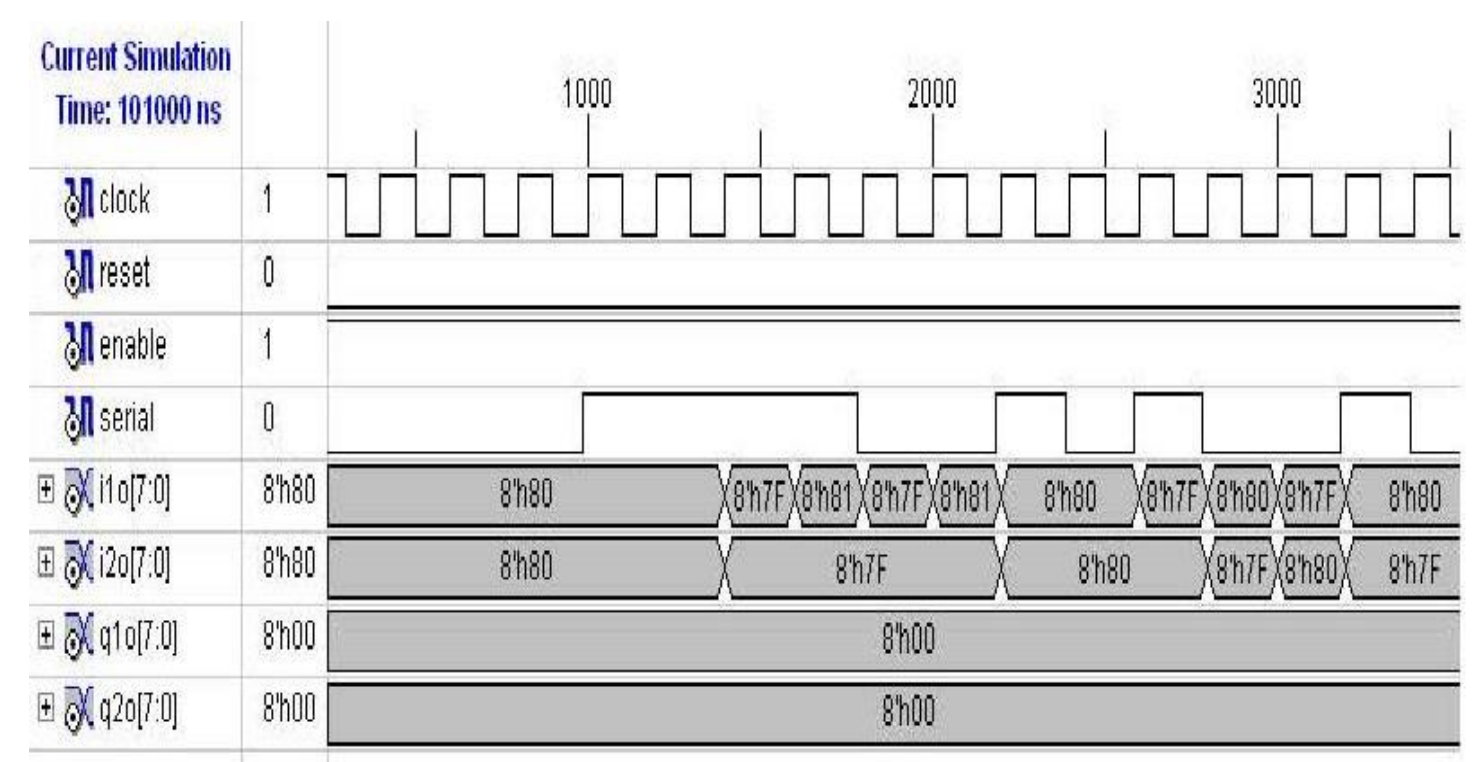

Figure (6): Time simulation waveforms of Alamouti transmitter.

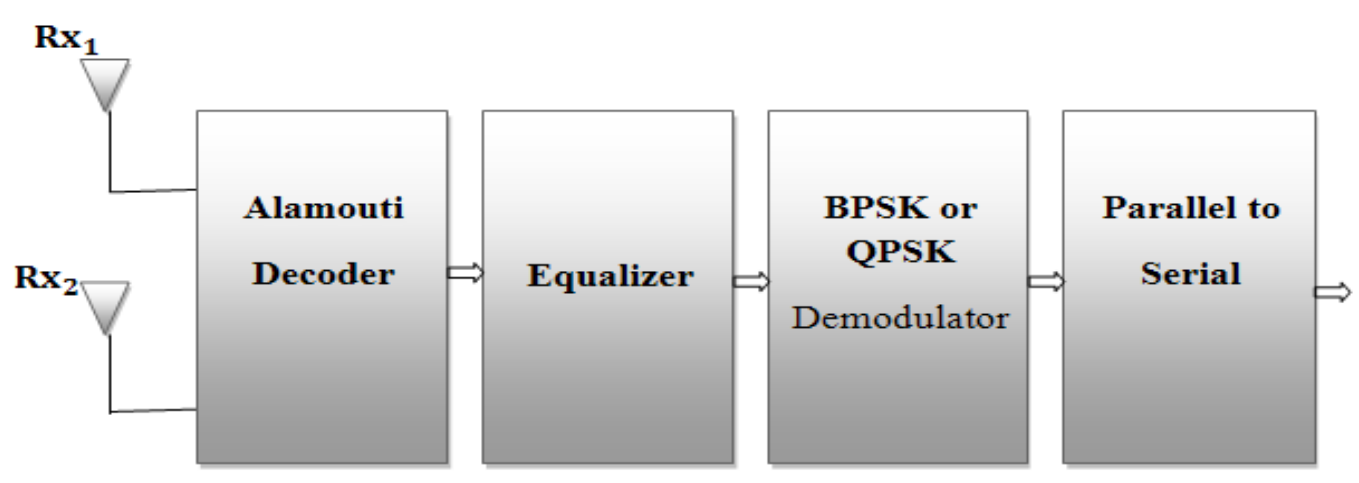

Figure (7) Block diagram of Alamouti receiver.

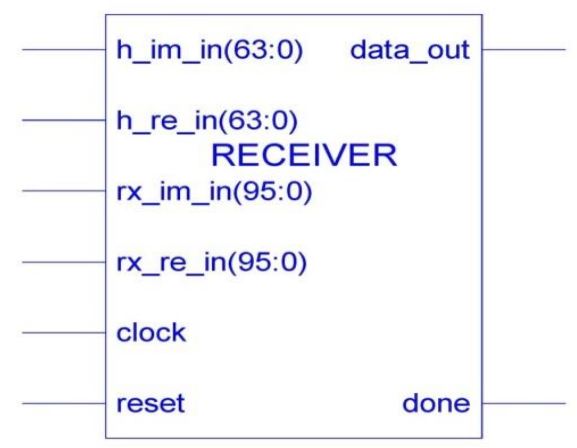

Figure (8): Alamouti receiver circuit. 


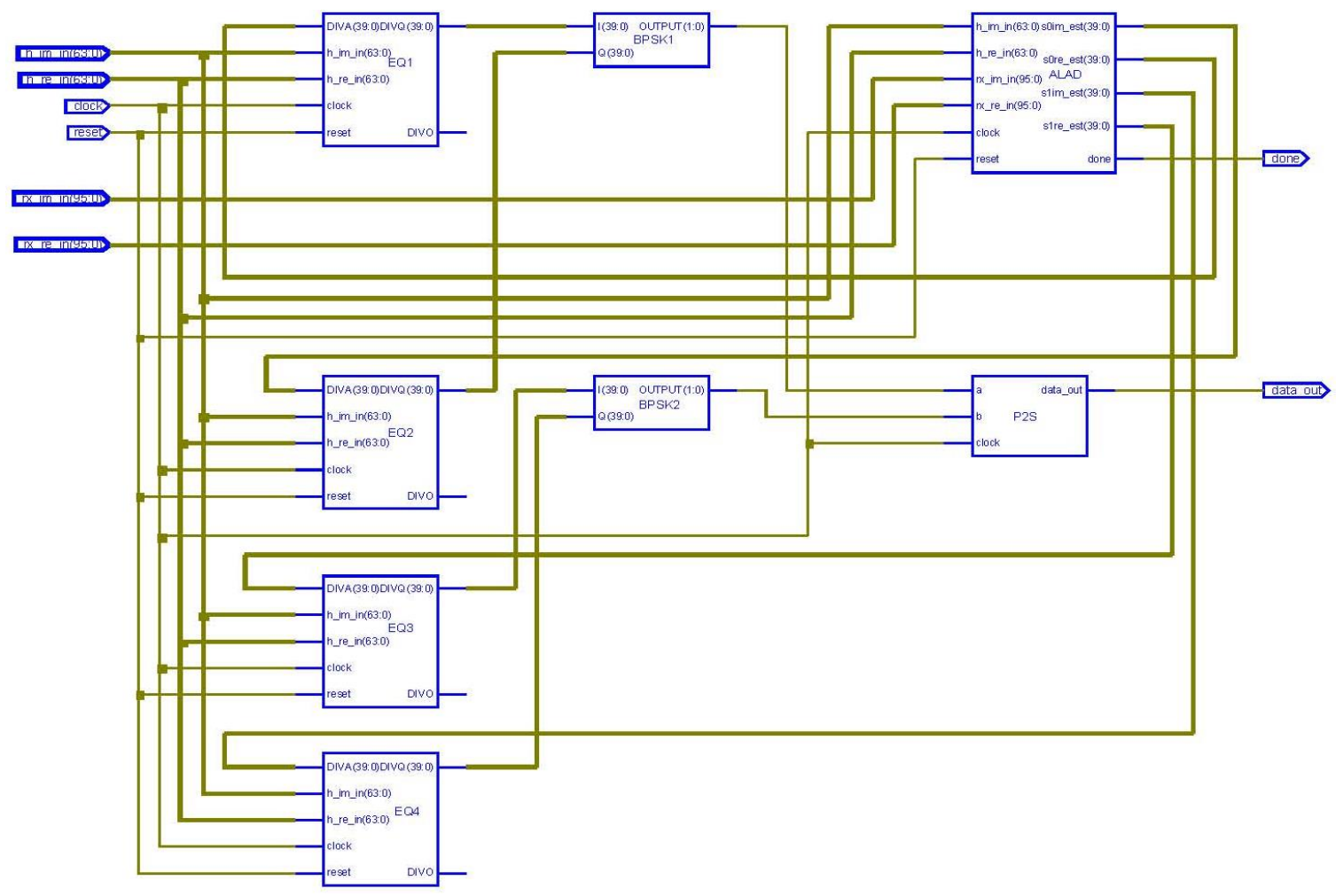

Figure (9): Alamouti receiver internal circuit.

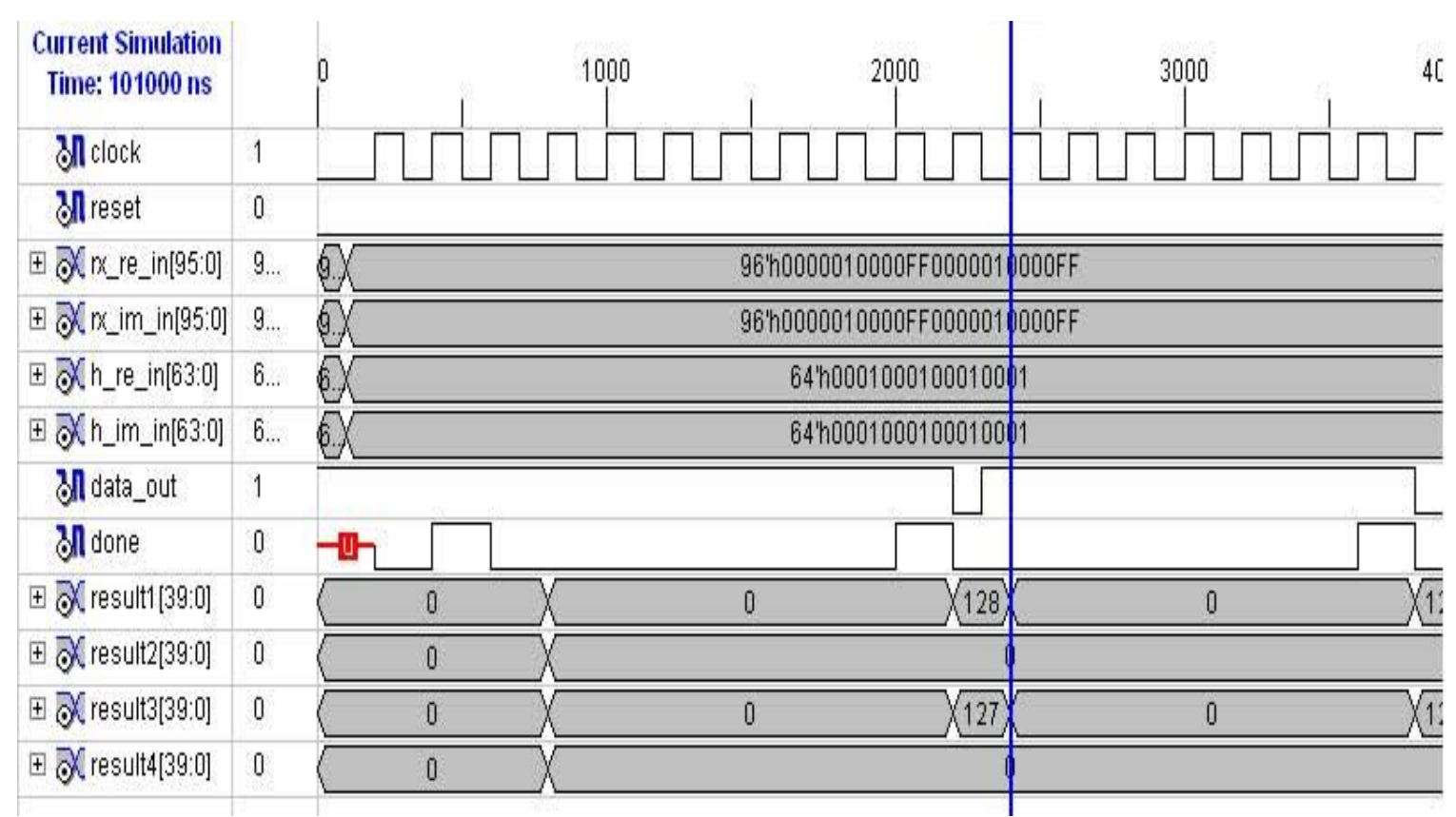

Figure (10): Resulting output waveform of Alamouti receiver. 


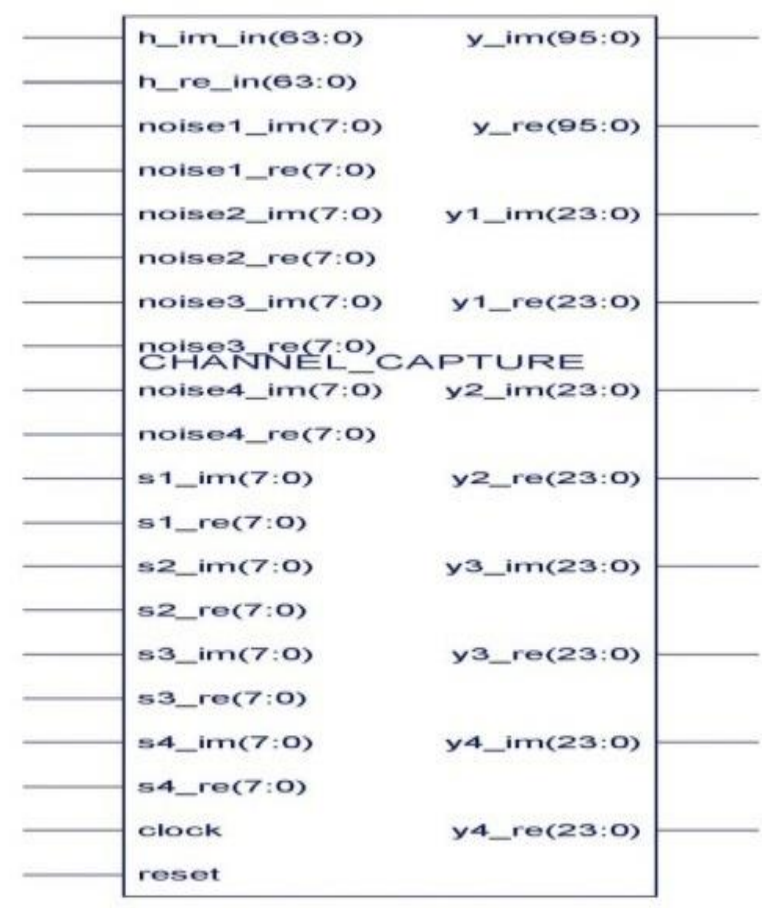

Figure (11): Channel module.

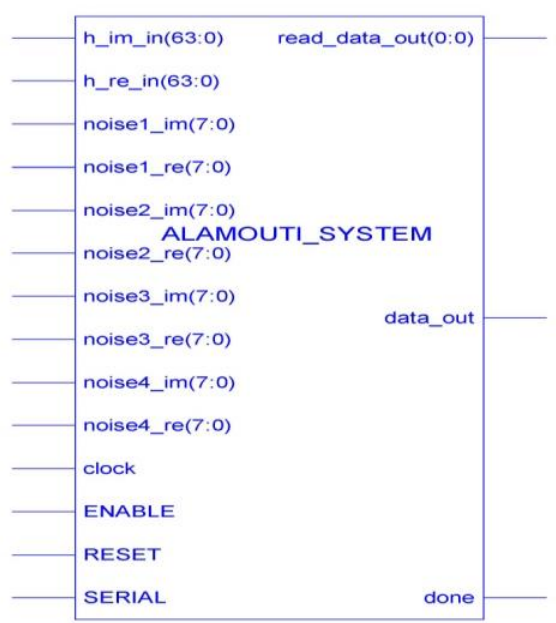

Figure (12): MIMO system with two transmitter and two receiver antennas. 


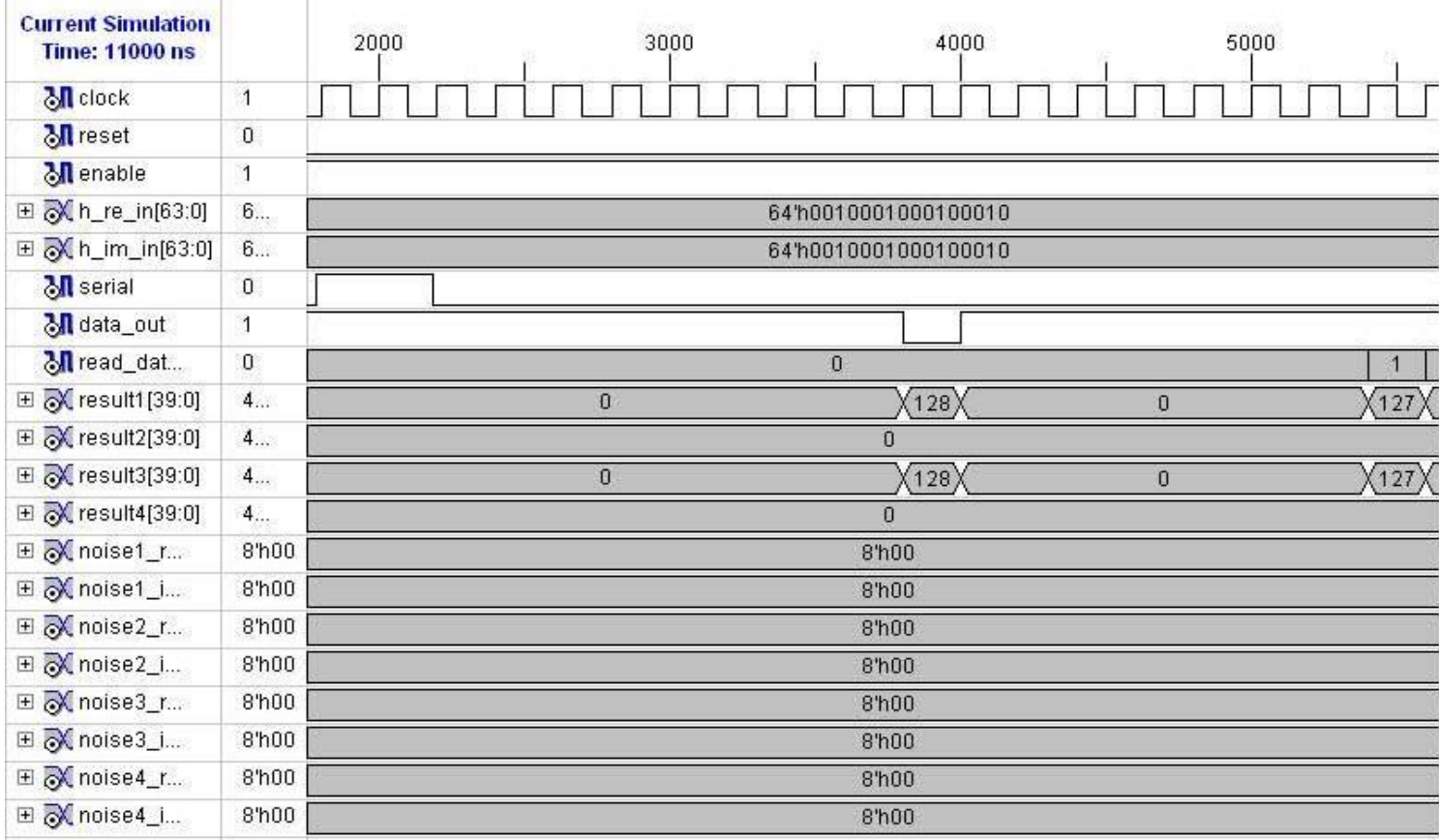

(A)

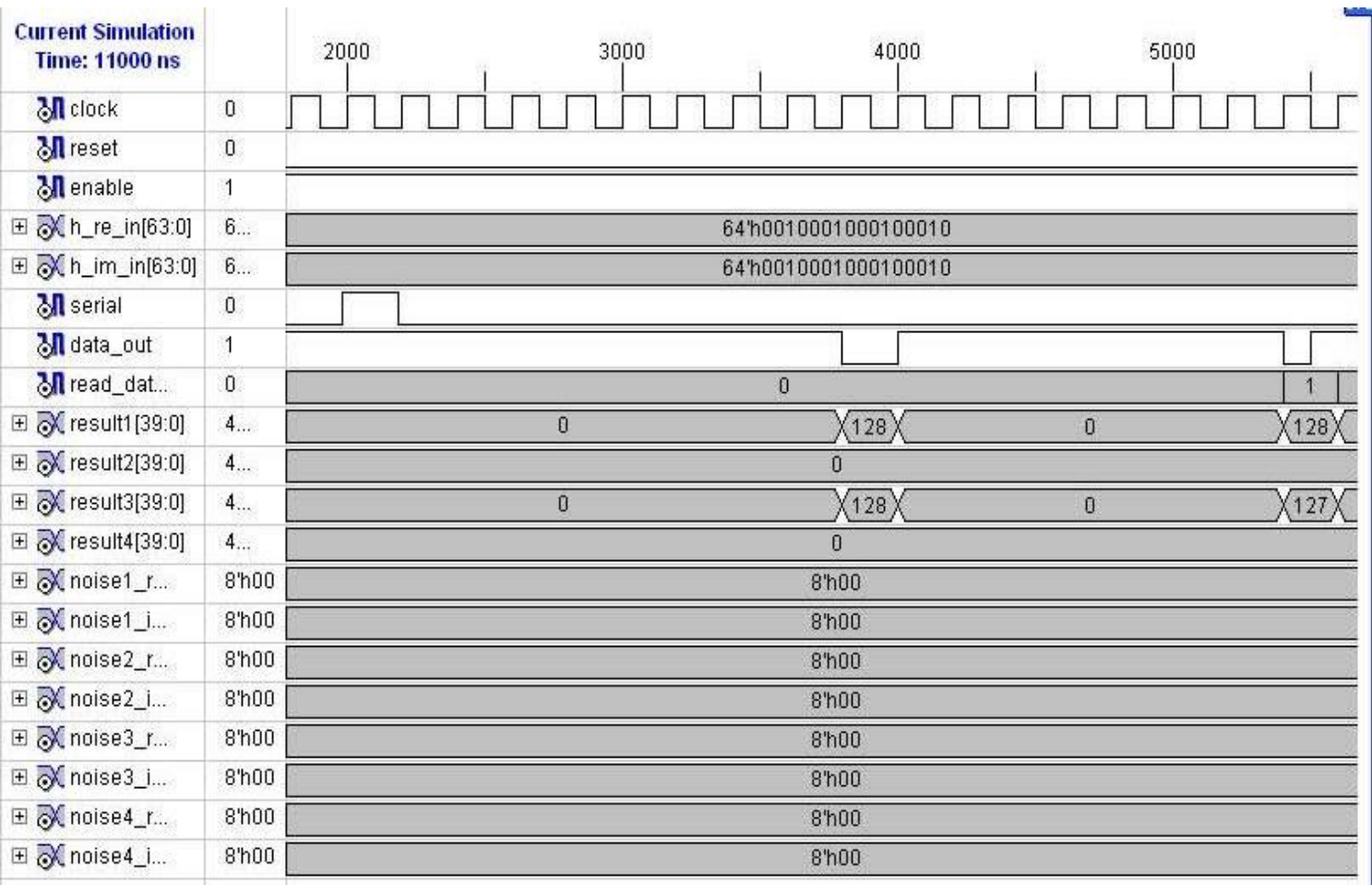

(B) 


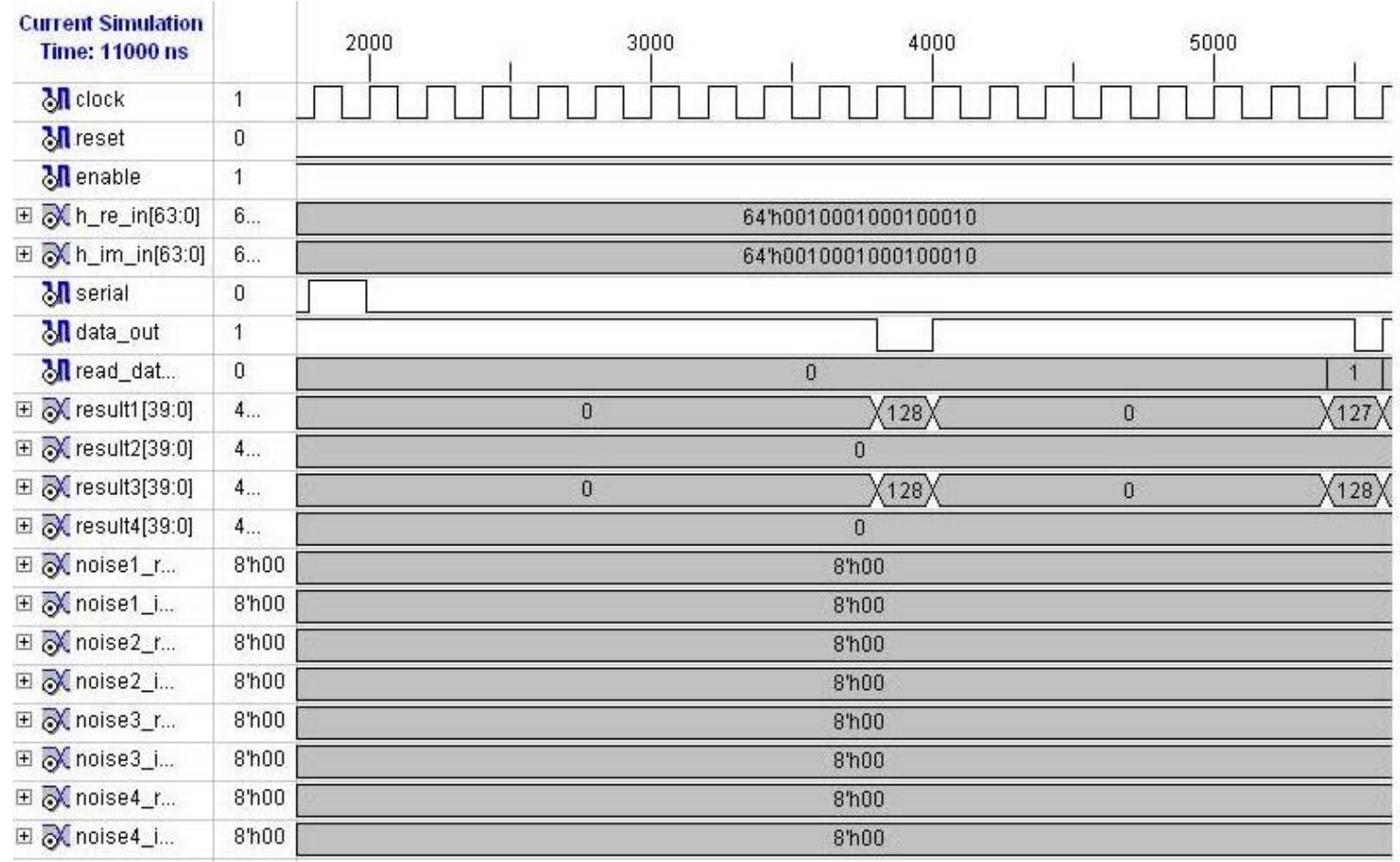

(C)

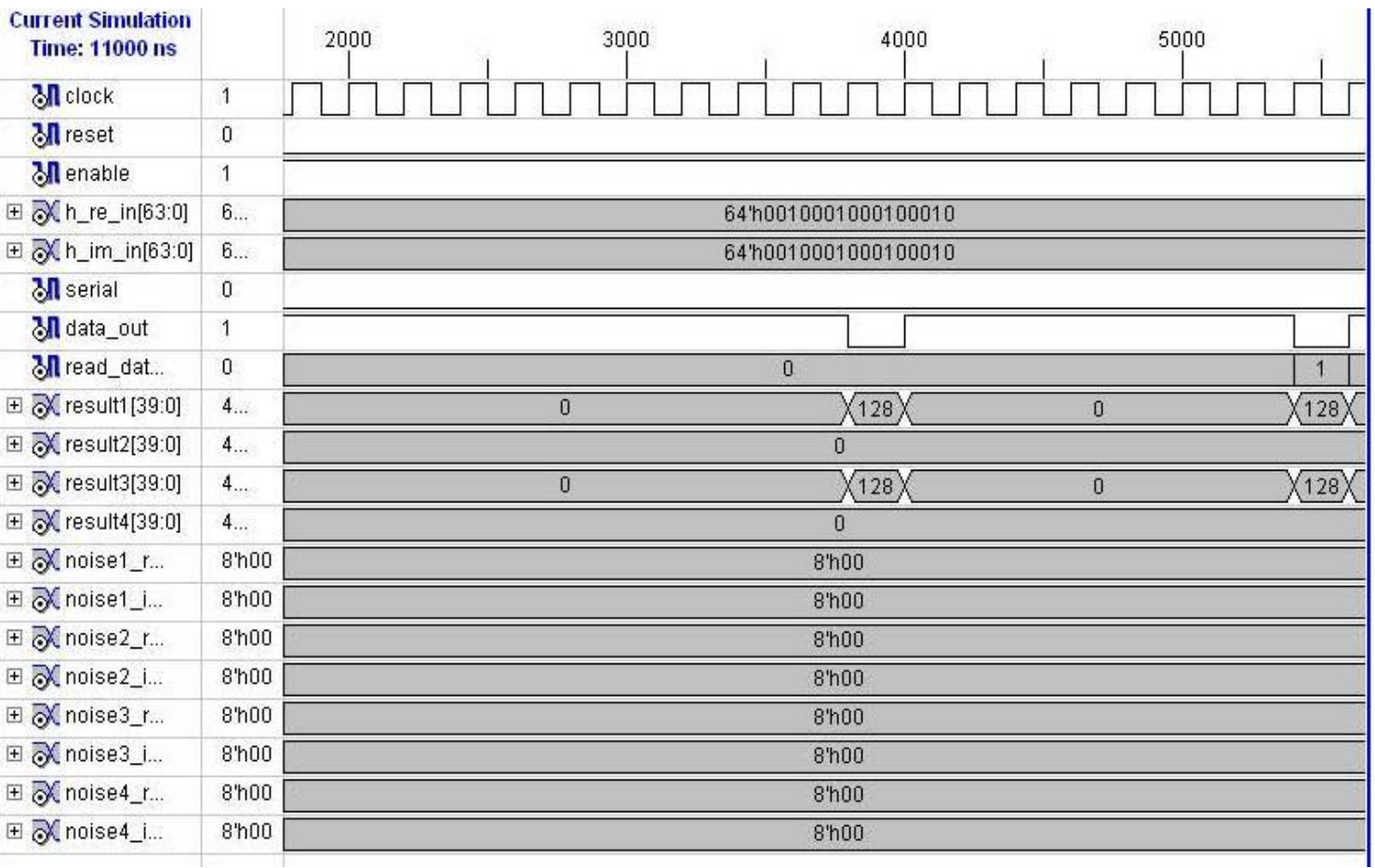

(D)

Figure (13): Output waveform of Alamouti system in ideal channel
(A) At serial input (11)
(B) At serial input (01)
(C) At serial input (10)
(D) At serial input (00) 


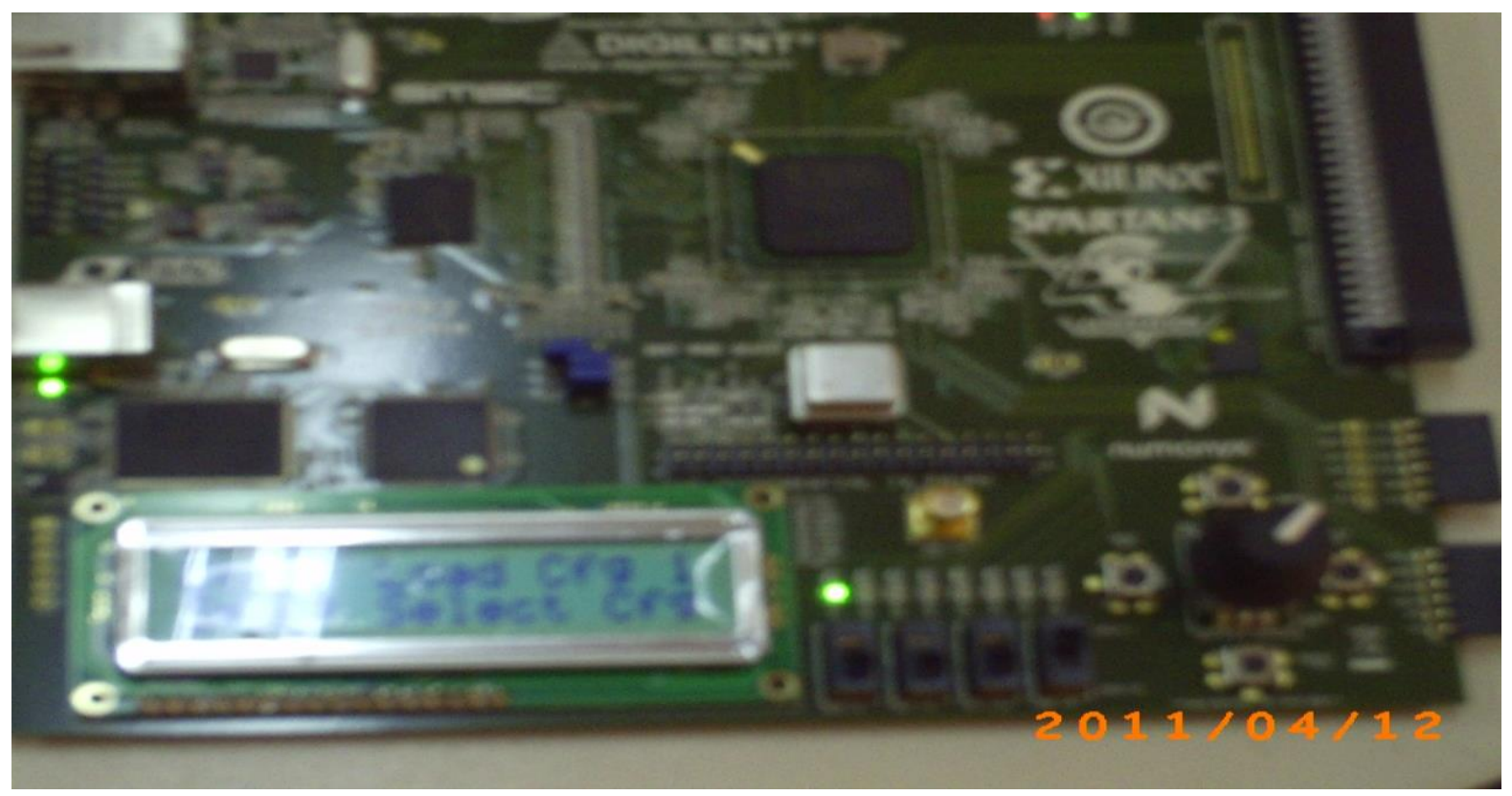

(A) Output data at two time interval for $\mathrm{Tx}_{1}$

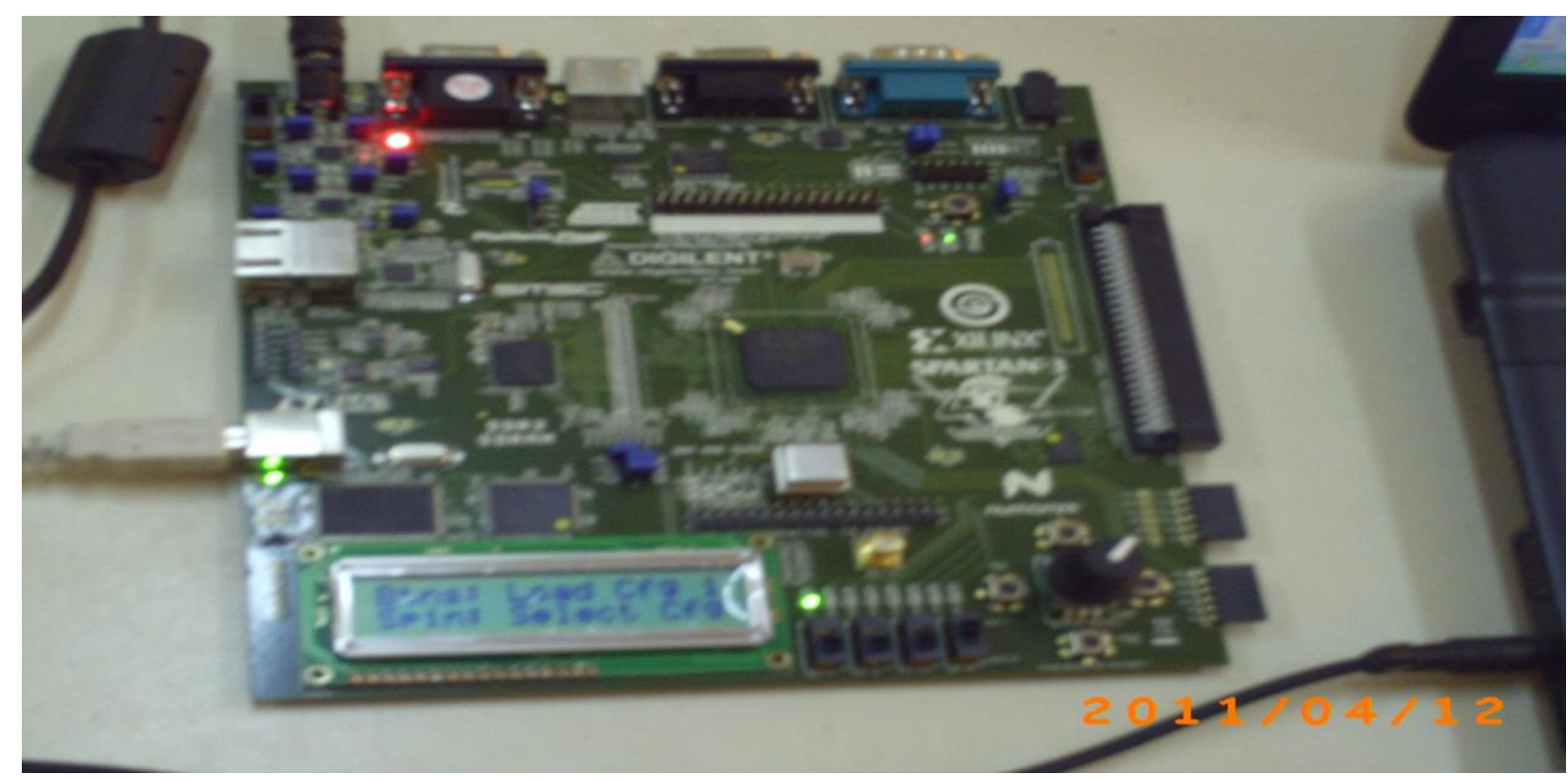

(B) Output data at two time interval for $\mathrm{Tx}_{2}$

Figure (15): Output data at two transmission antenna when serial data input (00). 


\title{
تصميم وتنفيذ نظام متعدد-الإدخال متعدد -الإخراج باستخدام مصفوفة البوابات المنطقية المبرمجة مئة
}

\author{
خالد عواد حمود 1، ادهم هادي صالح ²، وائل عبد الحسن هادي 3

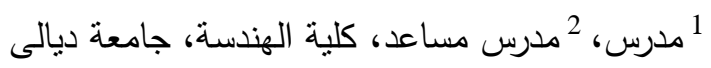

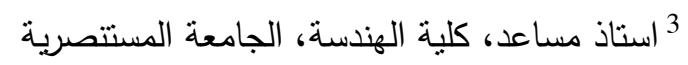

\section{الخلاصة:}

إنّ استخدام عدة هوائيات في الإرسال والاسنقبال (نظام MIMO) قبل على نحو واسع في السنوات الأخيرة كتقنية

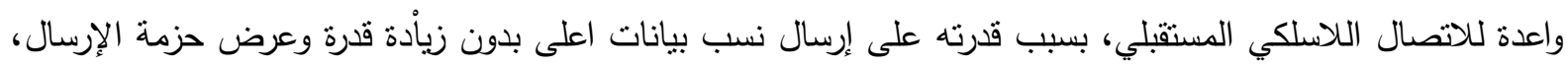

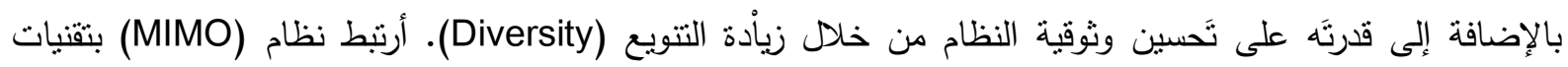

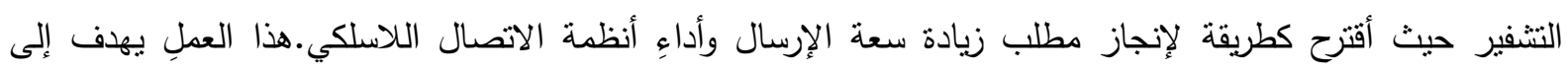
تصميم وتطبيق نظام اتصالات لاسلكي لعدة هوائيات مستتد على مخطط نتوع الإرسال ( Alamouti) باستخدام مصفوفة الإرساة

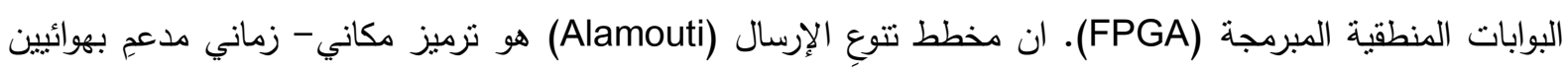
للإرسال وعدد غير محدد من الهوائيات المستلمة حيث يعرض هذا النطبيق تقنية التزميز المكاني وألزماني (ATBC)

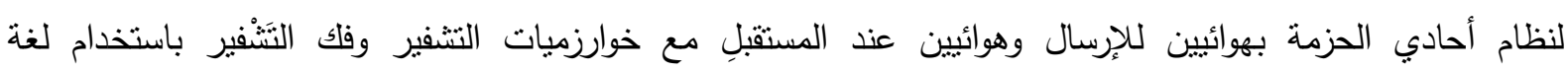
وهي لغةَ وصفية تستخدم لتصميم الدوائر الاككترونية.إن تتفيذ جزء الإرسال في هذا النظام قد نم عمليا باستخدام وتم تتفيذ جزء الاستقبال نظريا. وبالتالي فان تصميحَ نظام (Spartan 3Al3AN) 